\title{
Projeto Heliópolis: explicitação de expectativas de aprendizagem e construção de roteiros de leitura em contexto de inovação pedagógica ${ }^{1}$
}

* Professora da Universidade

Estadual de Campinas e doutora em educação pela

Faculdade de Educação da

Universidade de São Paulo.

** Pesquisadora do CENPEC.

*** Professor de Língua

\author{
Elisabeth Barolli* \\ Edna Aoki** \\ Luiz Cláudio Barretto***

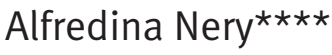

Conceição Cabrini ${ }^{\star \star \star \star \star ~}$

Portuguesa e Literatura nas

redes públicas municipal e estadual de São Paulo, foi coordenador-pedagógico do colégio Anhembi-

Morumbi e diretor da escola lumiar.

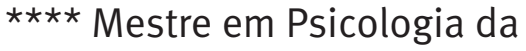
Educação pela PUC-SP. Atualmente é formadora do Programa Nacional pela Alfabetização na Idade Certa (PNAIC)/ Polo UFSCar).

$\star \star \star \star \star \star$ Doutora em Comunicação e Semiótica pela PUC-SP. É professora do ensino fundamental na rede privada.

Resumo: Este texto apresenta o percurso e os resultados de um projeto de assessoria realizado pelo Cenpec em uma escola pública municipal localizada no bairro de Heliópolis, no município de São Paulo, cujo Projeto Político Pedagógico prevê a construção de relações próximas com a comunidade, entendendo que a escola pode exercer um papel de transformação social. Orientados por essa diretriz e visando sanar as consequências mais imediatas do absenteísmo docente - como a necessidade de dispensar os alunos -, a escola passou por uma grande transformação em sua organização interna, adotando como modelo a Escola da Ponte, de Portugal. Os alunos não precisavam ser dispensados, mas surgiu um novo desafio: desenvolver profissionalmente os professores para que eles pudessem ensinar nas novas condições. O Cenpec foi chamado a intervir nesse contexto e, após diagnosticar possibilidades e restrições, optou-se por um trabalho com os professores que viesse a explicitar as expectativas de aprendizagem e a construção de roteiros de leitura.

Agradecemos a colaboração de Alfredina Nery e Conceição Cabrini. O projeto Heliópolis foi realizado sob a gerência de Cláudia Petri. 
Palavras-chave: Escola da Ponte. Expectativas de aprendizagem. Roteiros de leitura.

\section{Introdução}

As escolas das redes públicas de ensino têm enfrentado inúmeros desafios para oferecer à população um ensino de qualidade. A começar pelas condições do espaço físico escolar, que pode e deve ser um aliado na perspectiva de contribuir para a aprendizagem, é possível elencar muitas outras condições que poderiam contribuir para essa meta. Implementar um projeto pedagógico participativo que dê conta de uma gestão democrática do currículo, constituir uma equipe de profissionais - professores, diretores, coordenadores pedagógicos - estável, dignamente remunerada, bem preparada, motivada e com uma jornada de trabalho compativel com o ofício que exerce, ou mesmo efetivar um acompanhamento da aprendizagem dos alunos, são condições que têm se mostrado difíceis de serem alcançadas.

Ainda assim, temos notícias de iniciativas de muitas escolas que, apesar das adversidades encontradas, têm buscado, de forma criativa, desenvolver projetos político-pedagógicos que vão ao encontro de um ensino de qualidade. Acreditamos que conhecer as experiências dessas escolas pode ter importante papel no enfrentamento de dificuldades bastante recorrentes nas redes públicas de ensino. Importante não no sentido de reproduzir passo a passo essa ou aquela experiência, até porque cada escola é um caso singular, mas, sobretudo, para inspirar a criação de novas estratégias e novas formas de conduzir o ensino e sustentar o esforço dos estudantes na aprendizagem.

O que pretendemos aqui divulgar são alguns dos resultados da experiência que uma escola da rede municipal de ensino de São Paulo vem procurando desenvolver na perspectiva de vencer muitos dos desafios que se colocam atualmente para alcançar um ensino de qualidade. Inspirada nos pressupostos didático-pedagógicos da escola da Ponte, escola referência em Portugal, a Escola Municipal de Ensino Fundamental Presidente Campos Salles conferiu nova organização e dinâmica para seu currículo. Tal organização proporcionou - e continua proporcionando - à toda equipe de profissionais oportunidades para aprender a conduzir o processo de ensino, tendo como perspectiva de longo alcance o fortalecimento do papel transformador da escola no campo social. 
No lugar de centrarmos a discussão em aspectos que têm sido monotonamente referidos por diversos segmentos da sociedade, e que buscam explicar a insatisfação generalizada com o desempenho das redes públicas de educação, queremos aqui trazer uma contribuição do que pode representar uma busca por um ensino de qualidade. Como argumenta Carvalho (2007),

o conceito de "qualidade do ensino", em seu uso corrente, oferece uma série de riscos aos intelectuais e pesquisadores que sobre ele se debruçam. Dentre eles, o de ser tratado não como uma expressão polissêmica, capaz de nos remeter a diferentes interpretações $e$ categorizações de uma variedade de experiências, vivências e práticas sociais, mas como uma entidade fixa e imutável, cuja presença essencial seríamos capazes detectar - ou cuja grandeza pudéssemos medir - de forma inequívoca e a-histórica.

Procuramos aqui caminhar na perspectiva de oferecer elementos que emergem do processo vivido por essa escola, em particular no ano de 2011, período em que a mesma se apoiou na assessoria do CENPEC - Centro de Estudos e Pesquisas em Educação, Cultura e Ação Comunitária, e que, certamente, podem inspirar outras escolas e subsidiar mudanças profundas em seus currículos.

\section{A escola Campos Salles e suas demandas}

A Escola Municipal de Ensino Fundamental Campos Salles, DRE Ipiranga², está situada no bairro de São João Clímaco, na zona sudeste da capital paulista, no distrito de Sacomã. Integra o complexo Centro de Convivência Educacional e Cultural de Heliópolis ou, Polo Educacional e Cultural, como é conhecido, juntamente com a Escola Municipal de Educação Infantil Antônio Francisco Lisboa, os Centros de Educação Infantil (CEls) Heliopólis I, II e III e a ETEC - Escola Técnica Estadual Heliópolis, administrada pelo Centro Paula Souza. Atende mais de 1000 alunos nos níveis do ensino fundamental (anos iniciais e anos finais) e na modalidade de educação de jovens e adultos (EJA). O entorno da escola é densamente povoado e marcado por alto índice de vulnerabilidade social e organização comunitária, com atuação de várias lideranças numa região bastante conhecida devido à existência da maior favela de São Paulo em número de população: a favela de Heliópolis.

Atualmente, a escola desempenha importante papel no território, pois participa de projetos que buscam concretizar uma relação mais próxima entre escola e comunidade, reconhecendo o papel transformador da educação no campo social. O projeto pedagógico está assentado no princípio de tornar a escola um efetivo centro de liderança na comunidade onde está inserida, ocupando-se de temas e discussões que vão além dos assuntos referentes

2 Diretoria Regional de Ensino da rede municipal de Educação do município de São Paulo. 
ao desempenho dos alunos nos processos de ensino e de aprendizagem tais como: exclusão social, participação da comunidade, luta pelos direitos humanos (à vida, saúde, moradia, alimentação e educação). Com base na crença de que, a partir da educação é possível organizar e gestar uma sociedade mais justa e igualitária, embasada na cultura da paz, surge em Heliópolis um movimento que elege a educação como eixo norteador de todas as ações da comunidade. E, da aliança entre a União de Núcleos e Sociedades dos Moradores de Heliópolis e São João Clímaco (UNAS), uma das lideranças locais com maior representatividade no bairro e EMEF Campos Salles, iniciase um processo de transformação de Heliópolis em “Bairro Educador”.

Em 1995, quando assumiu a direção da escola, Braz Rodrigues Nogueira passou seis meses observando o cotidiano escolar de modo a identificar os possíveis problemas que marcavam a instituição. Rapidamente, dois foram detectados: a falta constante de professores e a consequente dispensa de alunos. Notou que sozinho, só por ser o diretor da escola, não conseguiria resolver o problema, já que a legislação concede aos docentes certo número de faltas abonadas e justificadas. Então, abriu a escola para os pais a fim de que eles a vissem por dentro, do jeito que ela era, com todos os problemas e contradições. Isso permitiria que entendessem aquela realidade e percebessem a importância de suas participações em prol de melhorias para todos. Procurou aproximar-se dos professores, pais, alunos e equipe técnica, promovendo reuniões sistemáticas para evidenciar a importância do trabalho pedagógico dentro da intersecção educação-comunidade. Ao mesmo tempo, os professores eram levados a melhor conhecer a região e as condições de vida das famílias atendidas pela escola. "Os problemas do entorno também são da escola. Se os direitos das pessoas que vivem ao redor do colégio não são atendidos, está comprometido o direito à educação", repetia Braz para os professores.

De todo modo, a ausência de professores e a dispensa de alunos acompanharam Braz por um bom tempo. Contava com a compreensão e colaboração dos professores presentes e, inúmeras vezes, “juntava turmas” de uma mesma série para não ter de dispensar os alunos antes do término do período. Foi nesse contexto que conheceu a experiência da Escola da Ponte e, percebendo estar enfrentando problemas similares de ensino e aprendizagem, começou a planejar mudanças no projeto pedagógico da EMEF Campos Salles a partir dessa referência.

Como muito divulgado na literatura especializada, em Portugal, a escola da Ponte implementou inovações em sua estrutura e organização de ensino para 
superar os problemas de isolamento dos professores, da ausência de projetos comuns, das repetições de lições e passividade dos alunos decorrente da forma tradicional de organização da escola. Não segue um sistema de seriação e nem ciclo e seus professores não são responsáveis por uma disciplina ou turma específica. José Pacheco (2012), coordenador da escola na época da implantação das inovações, esclarece:

No nosso projeto, é o sujeito que se constrói na atribuição de significado ao conhecimento coletivamente produzido. Os professores acrescentaram às tradicionais dificuldades de aprendizagem dos alunos o reconhecimento das suas próprias dificuldades de ensino. E procuram concretizar um ensino diferenciado onde um mesmo currículo para todos os alunos é desenvolvido de modo diferente por cada um. Não há um professor para cada turma, nem uma distribuição de alunos por anos de escolaridade. Essa subdivisão foi substituída, com vantagens, pelo trabalho em grupo heterogêneo de alunos. Dentro de cada grupo, a gestão dos tempos e espaços permite momentos de trabalho em pequeno grupo, de participação no coletivo, de "ensino mútuo", momentos de trabalho individual... que passam sempre por atividades de pesquisa.

Após muitas leituras, reflexões, debates e discussões, o Conselho da EMEF Presidente Campos Salles, apoiado pelas lideranças locais, aprovou em 2005 a implementação de uma metodologia de ensino inspirada na Escola da Ponte. Em 2008, as paredes de salas de aula comuns foram derrubadas e deram lugar a quatro salões denominados Salões de Estudo, local em que ocorre a maior parte das atividades escolares e onde, também, roteiros, sujeitos, tempos e espaços se tornaram uma desafiadora engrenagem pedagógica.

\section{A escola Campos Salles renovada: novos desafios}

Pouco tempo depois de as paredes terem sido derrubadas, transformando as salas de aula individuais em salões de estudo, a escola pôde testemunhar, quase que imediatamente, mudanças muito esperadas: os alunos não eram mais dispensados por falta de professores, ou pelo menos, eram dispensados com menos frequência, porque cada salão passou a agrupar três turmas ao mesmo tempo.

O salão de estudo abriga entre noventa e cem alunos de uma mesma série que realizam suas atividades sempre em grupos (quatro alunos por mesa), conversando, resolvendo e respondendo as questões propostas por roteiros de estudo. Sob a supervisão da coordenação pedagógica e direção, os roteiros de estudos são elaborados pelos professores (de cada disciplina), que se pautam nas expectativas de aprendizagem propostas pela Secretaria Municipal de Educação de São Paulo (SME-SP), bem como nos saberes e necessidades da comunidade. No salão, não há aula expositiva. Enquanto leem, discutem e 
escrevem, os alunos cumprem as tarefas do roteiro. Os professores circulam entre as mesas, checando o que está sendo feito e atendendo às demandas dos grupos. Não há sinais sonoros (campainhas, sinos, sinetas). A marcação do início e do final das aulas é feita pelo revezamento dos professores no salão.

Nos três turnos (manhã, tarde e noite), há intensa circulação de alunos por toda a escola devido à locomoção de pequenos grupos que têm atividades na sala de informática, na quadra de esportes, na sala de leitura, fazem encontros com o professor-monitor na sala de monitoria, ou ainda vão à sala de orientação.

A sala de monitoria é um espaço reservado para o professor-monitor acompanhar mais de perto um grupo menor de estudantes (em torno de 12 a 16 alunos), ajudando-os na organização e realização de suas atividades pessoais, seus registros e suas tarefas, orientando-os nos estudos e na convivência dentro e fora da escola. A sala de orientação é um espaço para encontros de professores e pequenos grupos de estudantes sempre que surge a necessidade de uma explanação mais detalhada nas tarefas contidas no roteiro, orientações específicas sobre determinada disciplina ou mesmo apresentação de um novo conteúdo.

O salão resolveu grande parte do problema da dispensa de alunos, porém, trouxe uma nova questão: nem todos os professores sentiam-se seguros no desenvolvimento de suas atividades naquele espaço, em particular os professores dos anos finais do ensino fundamental (EF2), que precisavam, a partir de então, dar conta de temáticas que não correspondiam às suas áreas de formação. Além disso, por se tratar de uma escola da rede municipal, chegavam professores de outras unidades escolares que haviam participado de concursos de ingresso, acesso ou remoção sem ter conhecimento da nova proposta que ali estava sendo implementada e, de um jeito ou de outro, tinham de se adaptar a ela. Outros chegavam por transferência, pois tinham conhecimento do projeto da escola e queriam ali trabalhar. Ainda, na EMEF Campos Salles, apenas menos da metade dos professores participavam das discussões coletivas proporcionadas pelas reuniões da Jornada Especial Integral de Formação (JEIF) ${ }^{3}$.

Atentos a esses fatos e insatisfeitos com a prática do trabalho coletivo até então desenvolvida, tanto entre alunos na realização dos roteiros de estudo,

A JEIF é uma modalidade de contrato de trabalho dos professores da rede municipal de ensino de São Paulo que prevê um número de horas de trabalho remuneradas fora da sala de aula. Parte dessas horas fora da sala de aula deve ser cumprida na escola, em reuniões de professores. 
como entre os professores na gestão do ensino nos salões e nos momentos de planejamento, Braz, equipe técnica, parte dos professores e do pessoal de apoio administrativo, além do pessoal da UNAS começaram a buscar parcerias que viessem a contribuir para o enraizamento do novo projeto. Foi assim que, em 2009, a partir dos primeiros contatos entre a UNAS e 0 CENPEC, concretizou-se uma parceria por meio de assessoria pedagógica com o objetivo de, numa primeira etapa, conhecer e compreender os processos pedagógicos que vinham sendo desenvolvidos na escola para a implementação do seu projeto pedagógico. Após esse diagnóstico, numa segunda etapa, as prioridades a serem trabalhadas seriam definidas, bem como construídos os procedimentos que efetivamente contribuíssem para atender as demandas da escola.

\section{A condução do processo de assessoria: apoios teóricos}

Desde os primeiros contatos do CENPEC com as equipes gestora e docente da EMEF Campos Salles, ficaram evidentes os esforços da escola no sentido de buscar meios para fincar raízes da inovação curricular que havia sido proposta. Com base nesse diagnóstico, tornaram-se explícitas algumas das principais fragilidades que o projeto da escola enfrentava e que indicavam, ao mesmo tempo, focos de atuação para um processo de assessoria que viesse a contribuir para implantar esse projeto. Sem dúvida, adentrar ao cotidiano de uma escola e constituir uma assessoria com essa característica não é tarefa trivial, inclusive pelo fato de incluir a formação em serviço dos profissionais.

Como considera Ponte (1998), falar em formação tem sido um enorme desafio, não apenas porque representa um campo de luta política e ideológica, mas também por implicar em inúmeras possibilidades de ações que, de modo geral, sempre encontram argumentos para sua defesa. Muitas investigações têm sido realizadas na perspectiva de problematizar e compreender processos de formação de professores (inicial e continuada), cujos resultados, certamente, auxiliam a propor ações, modelos e programas que têm como finalidade última subsidiar o professor em sua prática.

No entanto, ainda apoiados em Ponte (1998), considera-se que a ideia de formação contrasta com a de desenvolvimento profissional, embora não a exclua. E foi justamente essa perspectiva que orientou a condução da assessoria na EMEF Campos Salles, sobretudo em um particular aspecto: a formação, em geral, apoia-se num movimento que é essencialmente de fora para dentro, em que se espera que os profissionais assimilem os 
conhecimentos que lhe são transmitidos, enquanto que no desenvolvimento profissional, o movimento se realiza de dentro para fora, pois nesse caso cabem aos envolvidos com o projeto curricular as decisões sobre as questões que querem considerar, os projetos que querem empreender e o modo como os querem executar.

Ou seja, nessa perspectiva, os educadores deixam de serem objetos e passam a sujeitos da formação, concebida de forma ampliada na medida em que se realiza em torno de práticas efetivas e que é perspectivada de modo afavorecer o desenvolvimento profissional de todos envolvidos no projeto. Quando um educador, seja ele professor, diretor, ou coordenador pedagógico tem condições de refletir sobre sua prática, procurando respostas para questões sobre como concretizar determinados aspectos de currículo, está fazendo gestão curricular e desenvolvendo-se profissionalmente.

Nesse sentido, a condução da assessoria não poderia de forma alguma deixar de considerar o fato de que o coletivo da escola acumulava reflexões sobre as dificuldades que lhe interessavam enfrentar e, naquele momento de sua história, buscava auxílio para dar conta de suas tarefas. Ou seja, havia demandas concretas da escola para com ela mesma que surgiram no terreno da prática e que buscavam melhorar as condições de trabalho, bem como alcançar melhores resultados para seu projeto pedagógico.

Toda essa configuração remetia à possibilidade de pautar a assessoria nos pressupostos da investigação-ação ou, ainda, da pesquisa-ação críticocolaborativa. Pesquisas dessa natureza são aquelas que, no caso da escola e da formação de professores, buscam a transformação da realidade educacional e de aspectos da prática docente considerada necessária pelos próprios educadores. Daí receberem o adjetivo "colaborativa”, pois os pesquisadores ou assessores externos à realidade educacional não definem a priori o objeto da investigação e da busca de transformação. Além disso, assume-se que o processo de realização desse tipo de pesquisa não se dissocia de uma busca de compreensão mais ampla da experiência dos envolvidos, especialmente daquelas dimensões vividas como opressivas daí receberem o adjetivo “crítica” (FRANCO, 2005).

Há que se considerar ainda, como argumentam Zeichner e Diniz-Pereira (2005) que a pesquisa-ação tem o potencial de contribuir para que a escola possa se repensar e se refazer como instituição, melhorando suas relações com a comunidade e promovendo educação de qualidade para seus estudantes. Nesse caso, o processo de pesquisa-ação e seus resultados não se voltam exclusivamente para a melhoria do trabalho dos profissionais, 
mas se articulam com a responsabilidade social da escola na promoção da justiça social, econômica e política. Sem dúvida, em todo o tempo que lá esteve o CENPEC, a EMEF Campos Salles mostrou-se bastante comprometida com a melhoria da qualidade da educação e com as necessidades da comunidade que atendia. Assim, a opção por conduzir a assessoria pelos princípios da pesquisa-ação mostrou-se bastante oportuna e compatível com as necessidades da escola.

O PLANEJAMENTO DE ESTRATÉGIAS: A BUSCA PELA QUALIDADE DE ENSINO ALMEJADA

O levantamento de informações objetivas e a observação participante do CENPEC, na primeira etapa do projeto, originaram um vasto volume de dados sobre a escola e sobre a comunidade na qual ela está inserida. As análises desses dados e as discussões coletivas com a equipe escolar explicitaram os principais desafios que a escola se propunha a enfrentar. Assim, desse processo, a equipe escolar e a equipe do CENPEC elegeram para a segunda etapa do projeto o desenvolvimento das seguintes ações:

- Problematização e discussão dos roteiros de estudos até então elaborados, com os professores do EF2, tendo como perspectiva uma articulação mais efetiva das disciplinas de uma mesma área da organização curricular praticada pela escola, quais sejam: "linguagens e suas tecnologias”, constituída pelas disciplinas de português, inglês, educação física, artes, sala de leitura e informática; "ciências naturais e suas tecnologias", constituída pelas disciplinas de matemática e ciências naturais; "humanas e suas tecnologias", constituída pelas disciplinas de história e geografia.

- Elaboração dos roteiros com qualidade esperada e atrativa para alunos e professores, cuja centralidade no trabalho cotidiano favorecia uma necessária integração entre os conhecimentos curriculares a serem tratados com os alunos do EF2.

- Otimização do trabalho em grupo realizado pelos alunos no desenvolvimento dos roteiros e pelos professores na gestão do ensino nos salões de estudo.

ROTEIROS DE ESTUDO: MOTE PARA O DESENVOLVIMENTO PROFISSIONAL DOS PROFESSORES E PARA AS AÇÕES DA ASSESSORIA

As ações da assessoria envolvendo os professores do EF2 da EMEF Campos Salles tiveram como referência a demanda da escola quanto a necessidade 
de constituir roteiros de estudo que melhor favorecessem a aprendizagem dos alunos e a condução do ensino na instituição.

O trabalho desenvolvido nos salões de estudo com os grupos de estudantes, por ano de escolaridade, apoia-se, sobretudo, nesses roteiros que pretendem se constituir num instrumento motivador e de qualidade para alunos e professores. Também pretendem possibilitar a integração das disciplinas de uma mesma área de conhecimento e criar oportunidades para o aperfeiçoamento do trabalho em grupo pelos estudantes.

A escola ressentia-se do fato de que os roteiros ainda não correspondiam a essas expectativas e colocou para si justamente o desafio de caminhar nessa direção. Várias queixas foram feitas pelos professores em relação aos roteiros que estavam sendo utilizados, tais como: dificuldade de elaborar um roteiro que integrasse todas as áreas; o fato dos alunos não se dedicarem à leitura do roteiro e, portanto, não saberem o que era para ser feito; dificuldade dos alunos na sistematização das respostas às questões propostas; falta de material para pesquisa no salão; as amarras do livro didático; e poucas reuniões para se discutir os roteiros nas áreas. Além disso, embora a dinâmica escolar, inspirada na Escola da Ponte, exigisse a construção do trabalho coletivo dos envolvidos, os roteiros de estudos eram elaborados isoladamente, de maneira fragmentada.

Desse modo, as possíveis mudanças que esses roteiros poderiam comportar orientaram sobremaneira o processo de assessoria. Há que se destacar que a assessoria não perdeu de vista que, em torno desse mote, se estaria criando oportunidades para problematizar e discutir vários dos elementos que integram o processo educativo. De fato, esses roteiros constituíram-se em um dos principais elementos que sustentam a metodologia de trabalho da escola, pois são elaborados pelos próprios professores e, nesse sentido, são atravessados por diferentes questões de natureza pedagógica.

Assim, a equipe do CENPEC considerou fundamental a problematização desses roteiros junto aos professores, tanto no que se refere à definição de princípios para orientar sua elaboração, quanto de se avaliar conjuntamente seus limites e possibilidades efetivas.

\section{Os roteiros de estudo: um retrato inicial}

No final do mês de maio de 2011, quando chegou à escola, a assessoria pôde conhecer os roteiros que os professores vinham elaborando até então. Logo 
de início, o que chamou bastante a atenção foi o fato de que, de modo geral, os roteiros de todas as áreas se assemelhavam a uma lista de exercícios, distanciando-se de um instrumento capaz de contribuir com a aprendizagem dos alunos e, ao mesmo tempo se constituir num apoio para os professores conduzirem os trabalhos no salão de estudo, sobretudo se considerarmos que o professor precisa dar conta de temáticas que não correspondem à sua área de formação.

Sim, o roteiro está lá. Claro que se você é o professor que está fazendo o roteiro, você vai ter ciência do que está fazendo, mas os outros roteiros, das outras disciplinas, você não tem um acompanhamento... Não tem assim, digamos, não tem uma forma de uma pessoa expor o seu trabalho pro outro, pro outro poder... Quantas vezes eu tive que sair daqui, pra correr pro outro salão, pra perguntar pro professor: "olha, o que você está pedindo aqui" e tal...

(Prof. 3).

Outro aspecto que também chamou a atenção numa primeira análise dos roteiros foi o fato de que elencavam, logo no início, um conjunto de expectativas de aprendizagem que eram reproduzidas das Orientações Curriculares: proposição de expectativas de aprendizagem da Prefeitura de São Paulo. Essas expectativas eram apenas anunciadas aos alunos, mas não se fazia mais menção a elas no desenvolvimento do roteiro. Notou-se que algumas, inclusive, não tinham uma correspondência com o conteúdo que se pretendia desenvolver.

Com a intenção de problematizar a função dessas expectativas nos roteiros de estudo, foram levantadas junto aos professores questões como: elas devem estar explícitas nos roteiros? Devem ser "traduzidas" para os alunos ou estarem em linguagem técnica? E mais: elas estão efetivamente relacionadas ao trabalho proposto aos estudantes, quanto aos presentes nos roteiros e suas abordagens?

Para além dessas questões, observou-se que todos eles estavam fortemente apoiados em leituras de textos, sobretudo de livros didáticos. No caso de ciências naturais, em particular, o livro didático que orientava as leituras que os estudantes deveriam fazer para dar conta do roteiro, apresentava 0 conteúdo de forma sintética e de difícil entendimento para os alunos. 0 livro mais se assemelhava a um dicionário, repleto de definições, do que a um texto orientador para estudos e consultas sobre assuntos da ciência, além de reduzir o ensino de ciências naturais à apresentação de conceitos científicos, em geral, fora do alcance da compreensão imediata dos alunos. No caso de ciências humanas, semelhante ao caso de ciências naturais, foi proposto rever o uso do livro didático. Em outras palavras, esses fatos já acenavam para a necessidade de se problematizar os textos que deveriam contribuir 
para a aprendizagem dos alunos; ainda mais se se considerar o fato de que a escola contava com um razoável patamar de autonomia dos estudantes em favor da própria aprendizagem.

Assim, a seleção de textos para apoiar o trabalho dos alunos foi colocada como uma questão que merecia maior atenção de todos. Além disso, a assessoria apontou para o fato de que vários roteiros pediam para que os alunos lessem um texto excessivamente longo, correspondente a um capítulo inteiro, para depois fazer uma atividade de escrita de um texto de 10 linhas. Percebeu-se que esse encaminhamento era desmotivador para os alunos. A partir da leitura de textos de livros didáticos sobre temas científicos, é muito difícil, para um estudante do ensino fundamental, perceber o que é relevante destacar, isto é, que elementos ou que aspectos são importantes serem considerados para se alcançar as expectativas de aprendizagem. Portanto, um roteiro de estudo que pretenda privilegiar a autonomia precisaria, necessariamente, ajudar o aluno a navegar pelo texto com uma orientação mais específica quanto àquilo que é fundamental que ele se aproprie. Percebeu-se que os roteiros elaborados até então apresentavam várias fragilidades, seja no que se referia à forma, seja no que se referia ao conteúdo, bem como na articulação desses dois elementos.

Para enfrentar essas fragilidades a assessoria propôs aos professores um trabalho conjunto, no sentido de efetivar uma integração entre as áreas que não tivessem como eixo os conteúdos, mas o desenvolvimento da capacidade leitora dos estudantes. Essa opção pareceu ser bastante viável naquele momento, até porque o coletivo da escola não havia, até então, acumulado reflexões e práticas suficientes para investir numa abordagem interdisciplinar. Certamente, se a opção fosse essa, seria preciso disponibilizar muito mais tempo do que dispunha a assessoria e exigir dos professores e equipe técnica um investimento de energia que se mostrava impossível naquele momento. Ainda, em função desses fatores, essa opção incorreria num desgaste da própria assessoria e dos professores, podendo, ainda, se perder a oportunidade de alcançar alguns resultados mais rápidos que ajudariam, inclusive, a legitimar a assessoria e a fortalecer o grupo escola.

Integrar a área pelo desenvolvimento da capacidade leitora em todas as áreas mostrou-se uma opção acertada que, de certa forma, surpreendeu os professores, pois puderam perceber que é possível pensar a integração em outro patamar que não necessariamente o de conteúdos. Essa opção estava fortemente vinculada à possibilidade de produzir roteiros que, por um lado, contribuíssem mais com a condução das aulas nas salas de orientação e no salão de estudo e, por outro, que tivessem um potencial maior de motivar e 
de apoiar os alunos em seu processo de aprendizagem.

Sem dúvida, não bastava propor a integração entre as áreas por meio do desenvolvimento da capacidade leitora; certamente isso requeria a escolha de uma estratégia capaz de concretizar a proposta e de organizar os professores em torno de tarefas práticas. Como mencionado, os roteiros das diferentes áreas do conhecimento se apoiavam na leitura de textos, o que contribuiu para que a assessoria realizasse intervenções no sentido de problematizar junto aos professores a possibilidade de incluir nos roteiros de estudo um conjunto de orientações gerais de leitura que estariam perpassando todas as áreas do conhecimento e, neste sentido, integrando-as metodologicamente.

Desse modo, a partir do segundo encontro com os professores, para subsidiálos no que se refere às habilidades de leitura, foram discutidas as "Estratégias de leitura" baseadas no livro de Isabel Solé (2000) que sinalizam para a organização de três movimentos na leitura de um texto:

1. Antes da leitura: cujo objetivo é trabalhar com o repertório do leitor para a compreensão do texto, indicando os elementos contextualizadores nele contidos (autor, portador, assunto e tema, gênero textual), por meio do levantamento dos conhecimentos prévios/hipóteses do leitor.

2. Durante a leitura: cujo objetivo é apresentar alguns aspectos orientadores da leitura ao leitor, por meio do levantamento de dados que os auxiliem na construção dos sentidos do texto em questão.

3. Depois da leitura: cujo objetivo é ampliar as referências culturais dos leitores, por meio da relação entre as várias áreas do conhecimento implicadas no texto trabalhado, bem como favorecer a construção de sínteses dos alunos do texto lido, que representa, sem dúvida, uma forma de compreensão leitora.

\section{0 processo de reelaboração dos roteiros de estudo}

A proposta de incluir orientações de leitura nos roteiros de estudo foi apresentada, discutida e sugerida aos professores para que ela apoiasse a elaboração de seus próximos roteiros. 0 intuito era possibilitar-lhes a reflexão sobre as condições de produção dos roteiros, para que pudessem qualificar melhor essa importante ação didática junto aos estudantes. Esse movimento foi desconstruindo a ideia dos roteiros como listas de exercício, com as quais os alunos podiam se relacionar burocraticamente. Assim, se estabeleciam outras necessidades que se relacionam estreitamente com a concepção de 
texto como interlocução, como interação entre sujeitos.

Considerando que as condições de produção de todo e qualquer texto escrito colocam em pauta vários constituintes, como autor e leitor (interlocutores), finalidades de quem escreve e de quem lê assuntos e temas, além das estratégias de como escrever e ler, a assessoria foi se constituindo de sucessivas explicitações destes elementos aos professores, na direção destes relacionarem seus próprios processos de escrever e de ler aos processos dos alunos.

Para isso, a assessoria partiu de exemplos concretos, ou seja, analisava alguns roteiros "antigos" dos professores e depois os roteiros reconfigurados, proporcionando momentos em que pudessem se perceber não somente como autores, mas também como leitores de seus roteiros e de seus colegas. A aposta aqui, além de garantir o processo de produção/leitura dos roteiros, era a de um trabalho coletivo do grupo de professores. Nesse sentido, se todos compreendessem os roteiros como um gênero textual cujos assuntos e temas são pertinentes a cada disciplina ou área, era possível articular mais e melhor o trabalho pedagógico da escola, para além do "artificialismo do tema comum" a todos. 0 caminho seria na direção de o professor se sentir mais autônomo para auxiliar os alunos naqueles momentos, independentemente da sua disciplina de origem.

No caso da etapa "antes da leitura" enfatizou-se a necessidade de apresentar uma problematização para os alunos que potencialmente os motivassem para a realização da leitura do texto, bem como das atividades propostas no roteiro. Ficou evidente para os professores que não é muito trivial elaborar questões dessa natureza, ou seja, não há uma fórmula que permita de imediato constituir uma questão problematizadora. A questão só poderá ser assim qualificada na medida em que contribuir para que os alunos sintamse desafiados a pensar para além daquilo que já sabem, isto é, sintam-se mobilizados a buscar uma solução que não depende exclusivamente de sua memória, que tenha o potencial de desencadear a curiosidade e a reflexão. Percebeu-se que encontrar questões dessa natureza exige do professor conhecimento de seus alunos, dos conteúdos selecionados e, sobretudo, de um esforço no sentido de elaborar um questionamento que atenda a alguns importantes requisitos, tais como:

- Não ser desvinculado do universo de conhecimento do aluno.

- Ser inteligível o suficiente para que os alunos compreendam o que foi perguntado.

- Suscitar um mistério que pode motivar os alunos a se implicarem com 
a questão.

- Não ser de difícil abordagem, contribuindo para que os alunos sintamse seguros e capazes (hábeis e competentes) para levantar hipóteses de solução.

- Não ter uma solução evidente e imediata, nem um algoritmo que permita alcançar rapidamente a solução.

A partir de índices textuais como título, ilustrações, observações, etc, os alunos fariam previsões sobre o texto, bem como fariam perguntas que gostariam de ser respondidas pelo que iriam ler.

$\mathrm{Na}$ etapa "durante a leitura”, enfatizou-se que, nas orientações, era importante que o professor, de certa forma, desconstruísse o texto, sinalizando e pontuando os aspectos que considerava mais fundamentais de serem observados, além de chamar a atenção dos alunos para a maneira como as ideias se encontravam articuladas, ou ainda relacionar as eventuais ilustrações com o corpo do texto.

Para todos foi evidente que a leitura de um texto requeria habilidades nada triviais, que não prescindia de um leitor com capacidade de análise e de síntese para que pudesse apreender e organizar as informações mais relevantes. Pontuou-se, ainda, o fato de que aquilo que o autor do texto, por ventura, pretendia dizer não se revela tão importante, até porque há que se considerar que, em última análise, não há mensagem transcendental veiculada pelo texto. Ou seja, o professor é quem oferece os operadores de leitura para os alunos; "os óculos" que considera importante para utilizarem durante a leitura. Obviamente, depois os alunos poderão fazer muitas outras leituras com os operadores que quiserem, mas seria fundamental, num primeiro momento, que eles lessem a partir dos operadores de leitura fornecidos pelo professor.

Orientou-se, então, a produção dos roteiros no sentido de os professores avaliarem a pertinência de propor e de alternar questões que pudessem cumprir diferentes finalidades para englobar habilidades/expectativas de aprendizagem previstas: localizar informações de um texto, inferir informações, avaliar informações. A primeira finalidade exige uma leitura "na linha”, ou dito de outra forma: é basicamente recuperar o que está dito e escrito no texto. A segunda pede uma leitura "entre as linhas", ou seja, o que está dito, mas não escrito, mas sim subentendido, pressuposto, etc. A terceira pede uma leitura "por trás das linhas", isto é, o leitor precisa relacionar o que sabe, o que o texto 
trata e quais são os sentidos sobre aquele tema que está no mundo.

Geralmente realizado no salão de estudo, o “durante a leitura” acontece sob a orientação de três professores de diferentes disciplinas que estão com os grupos de alunos. Dessa maneira, um bom roteiro de estudo, orientador da leitura/estudo dos alunos é um importante instrumento didático, possibilitando que, no salão de estudo, o professor seja um mediador da ação pedagógica, independente de sua especialidade curricular.

Finalmente, no que se refere à etapa "depois da leitura”, considerou-se a importância não só de orientar uma produção pessoal dos alunos baseada na leitura, mas também de apresentar outros textos que tratassem do mesmo assunto, mas com abordagens diferentes. Nesse sentido, ponderou-se a possibilidade das orientações de leitura apontarem para a elaboração, pelo leitor, de pequenos textos ou de esquemas que "traduzissem" as informações mais relevantes que pudessem ser extraídas com base nos operadores de leitura fornecidos. Mais especificamente foi explicitado que essa etapa correspondia ao momento das construções de sínteses do texto - que podem ser orais, escritas ou produzidas em diagramas, referentes às explicações das passagens mais difíceis do texto lido; das trocas de impressões sobre o que se leu e da ampliação do que se aprendeu, com acesso ou pesquisas a outros textos sobre o mesmo tema, o mesmo gênero textual, diferentes autores etc.

Durante os encontros procurou-setambém marcar o fato de que esse procedimento de leitura se configurava como parte de um roteiro de estudo. Roteiro que por sua vez precisa ser pensado para dar conta de demandas de uma escola que pretende intervir a favor da autonomia dos estudantes na construção de suas próprias aprendizagens e da perspectiva de que os estudantes constituam efetivamente um trabalho em grupo numa dinâmica exitosa.

A fim de auxiliar os professores no processo de reelaboração dos roteiros de estudo, em particular no que se refere às orientações de leitura dos textos, a assessoria lançou mão basicamente de duas estratégias. Na primeira, apresentaram-se para os professores exemplos (produzidos pela equipe do (ENPEC) de possíveis abordagens para o processo de leitura de um texto previamente escolhido. Esses exemplos foram discutidos tanto nas áreas específicas, com base em textos também específicos, como no coletivo dos professores, por meio de textos mais abrangentes de cunho interdisciplinar. A segunda estratégia foi acompanhar, durante os encontros e por meio eletrônico, a elaboração dos roteiros pelos próprios professores, cujas versões recebiam comentários e sugestões de modificações da assessoria. Em muitos casos, esse procedimento exigiu uma atenção frequente da assessoria, pois 
esse processo implicava em retrabalhar o roteiro.

É importante atentar para o fato de que essa estratégia fez com que a assessoria compartilhasse mais frequentemente documentos pela internet, viabilizando, desse modo, um processo de produção coletiva. Além disso, permitiu que a assessoria sustentasse os esforços dos professores na reelaboração de suas produções, valorizando esse esforço e intervindo para que não se sentissem à deriva no enfrentamento do desafio. Ainda, destaca-se que a vivência dos professores no processo de escrever pode ajudar a melhor compreender o processo de ler e escrever de seus alunos, favorecendo situações de leitura e produção de escrita em que os professores precisam ajudá-los.

\title{
A CONSTITUIÇÃO DE UMA PARCERIA EXITOSA PARA O DESENVOLVIMENTO PROFISSIONAL DOS PROFESSORES
}

$\mathrm{Na}$ interpretação da assessoria e dos professores, o esforço conjunto na direção de conceber roteiros que melhor favorecessem a aprendizagem dos estudantes ao longo de 2011 foi exitoso em vários aspectos. Diversos depoimentos coletados valorizam a constituição de uma parceria efetiva:

\begin{abstract}
O CENPEC veio mesmo pra ajudar, porque, tanto para os professores, quanto para os alunos, o CENPEC deu novas visões. E o legal é que eles não trazem nada pronto. Isso eu achei muito bacana. Eles não chegam aqui e: "olha, vamos fazer isso!". Trazem as ideias e acatam muito as ideias da gente, porque já enxergam que isso só vai dar certo se partir da gente. (Prof. 1)

Eu senti uma grande dificuldade em realizar esse novo roteiro, até porque eu estava acostumada com o outro, e quando a gente já está acostumado... vamos começar o nosso. Aí começamos .... Eu fazia o novo roteiro e aí mandava, aí ela mandava o que tava, o que deveria corrigir, mas isso discutindo. Não é que ela impunha. Havia uma discussão entre nós. (Prof. 1)
\end{abstract}

0 processo realizado com esse esforço conjunto, tendo como eixo a reelaboração dos roteiros, foi, em boa parte, ao encontro da demanda dos próprios professores no sentido de fortalecer o coletivo docente. É possível afirmar que os encaminhamentos e as escolhas da assessoria para esse Mas a gente tá caminhando pra isso [trabalho coletivo]. Foi um processo de
momento de interven caño nas questó in internas da escola foram acertadas,
amadurecimento, desde que nos começamos la com a nossa parceria com voces, isso vem

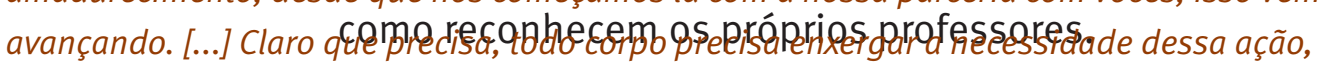
porque a escola... não adianta culpar o aluno do fracasso escolar. (Prof. C2)

Isso é um desafio, desafio para nós professores, para nós adultos, aprendermos a trabalhar em grupo. [...] Então é complicado, é uma coisa de um ser humano mesmo, cada um tem um ritmo. $O$ único problema que eu vejo nos grupos, é isso. Mas não é um problema dos alunos. Nós também precisamos aprender isso. (Prof. C3) 
Sem dúvida, seria pretensão esperar, a partir do trabalho realizado em menos de um ano, um grande avanço em termos de constituição de um coletivo docente, com estabelecimento de uma dinâmica por completo operativa e relativamente focada, sobretudo em torno dos roteiros. De fato, trabalhar em grupo requer tempo de amadurecimento e não é uma opção automaticamente vencedora.

A qualidade requerida do produto do trabalho em grupo, o quanto essa organização pode contribuir para a aprendizagem de seus membros individual e coletivamente, o reconhecimento de que se pode aprender uns com os outros, requer esforços não elementares. A possibilidade de constituir um coletivo escolar também se concretiza na medida em que os professores se debruçam sobre casos concretos difíceis de entender, casos que desafiam para além do já conhecido. Buscar soluções para casos complexos requer competência coletiva que é mais do que a soma de competências individuais. Constituir essa competência é situar a escola como local de formação, é criar rotinas sistemáticas de acompanhamento e de reflexão sobre o próprio trabalho docente, é reconhecer que não existem respostas prontas para todos os dilemas e impasses vividos pelos educadores na escola. Esses casos concretos constituem-se em oportunidade para os professores organizaremse como uma comunidade que se propõe a investir com persistência profissional, com compromisso social e vontade de mudança, na análise aprofundada e coletiva das situações (NÓVOA, 2009).

Especificamente em relação aos roteiros, é possível afirmar que houve considerável avanço em termos da relação forma-conteúdo. Verificam-se mudanças significativas quando comparados com aqueles encontrados no início do processo. Já não se constituem mais como listas de exercícios acompanhadas de uma lista prescritiva e engessada de expectativas de aprendizagem. Trazem agora a autoria dos professores, pois as expectativas são reelaboradas ou modificadas de forma articulada e consistente com o conteúdo que pretendem desenvolver.

Por que só colocar lá expectativas de aprendizagem numa linguagem super hiper técnica não só pra eles, mas até pra mim, [fazia com que houvesse] algumas coisas que eu precisava realmente consultar no dicionário. Você imagina pra eles... Eu fui vendo que eu poderia falar das expectativas de uma forma mais tranquila, traduzindo inclusive pra linguagem deles, pra eles saberem o porquê daquelas atividades, isso foi bacana. (Prof. 2)

Embora ainda seja necessário os professores selecionarem textos mais atrativos e pertinentes à faixa etária para compor os roteiros de estudo, é importante salientar que houve avanços nesse sentido à medida que alguns professores se mostraram implicados com a elaboração desses textos ou 
mesmo com a adequação e seleção de trechos de livros didáticos.

O processo de reconcepção dos roteiros, por meio do desenvolvimento da capacidade leitora dos alunos, trouxe ganhos, inclusive, para a prática dos professores na construção e aperfeiçoamento de saberes docentes, sobretudo quanto ao conhecimento didático do conteúdo ${ }^{4}$, o conhecimento do aluno e o conhecimento do próprio conteúdo que ensina. Vários professores mostraramse entusiasmados e satisfeitos com o potencial dessa nova concepção, em especial no que se refere à etapa "antes da leitura” em que precisaram investir na proposição de problematizações e com isso conduzir o ensino nas salas de orientação de forma mais satisfatória do que anteriormente o faziam.

De modo geral, é possível perceber nos depoimentos que os professores consideram que suas práticas se modificaram e, mais importante, que 0 processo de elaboração dos roteiros, que inclui as orientações de leitura, abriu possibilidades para refletirem as próprias práticas, questão que mais e mais vem sendo ressaltada pela literatura especializada como fundamental no ofício do magistério.

O "antes da leitura", eu achei essencial, eu nunca tinha feito isso, eu explicava o roteiro, aí rolava aquela conversa, mas não era nada com que eles já sabiam, entendeu, ou partia do ponto de que eles já sabiam isso era um erro meu. Outro erro meu, eu não apresentei o livro didático para eles, eu parti do ponto que eles já conheciam, e eles... e ainda mais a quinta série... Essa aula foi superinteressante pra eles. Por que eles até conhecem o livro, mas eles não têm a ideia de índice, não sabem o que é isso, pra eles é tudo novo. E eu tinha esse erro que achava que já sabiam. E o "antes da leitura" eu achei essencial também por que assim você percebe o que cada um sabe a respeito, e rola aula mais dinâmica, eles falam mais, que antes era mais eu falando, mais tradicional. (Prof.1)

Então, agora, no último roteiro ela deu a ideia, que estou dando frações, de trazer bolo, ou então trazer uma torta...Nossa como eles adoraram isso!... Toda vez que eu vou parar agora pra fazer, eu tenho que fazer várias vezes. Eu faço, aí releio, ah não, não tá legal, entendeu? Isso você vai crescendo também, né?... Aí com o "antes da leitura" eles descobrem que eles sabem muito, e com isso eles vão tendo mais interesse... E também mais direcionado pra leitura, que é o principal. (Prof.1)

O conhecimento didático do conteúdo (ou PCK, do inglês knowledge pedagogical content) vem a ser o acordo ou intersecção entre o conhecimento do conteúdo e o conhecimento didático, incluindo aí as formas de representação e reformulação do assunto de modo a torná-lo compreensível para os alunos. Para muitos pesquisadores da área de educação, um professor habilidoso é aquele que pode abrir um número significativo de diferentes entradas para o mesmo conceito, porque os alunos diferem na maneira como têm acesso ao conhecimento, tanto em termos de interesse quanto de estilos. 
Eu acho assim, o roteiro [...], está se tornando algo assim que já introjetei. E sem perceber... outro dia estava verificando meus diários, nesses dias que estou sem alunos na outra escola, eu comecei a perceber que, meio que automaticamente, eu estou colocando roteiro pra eles. Eu me peguei fazendo isso outro dia. Mas como nós não temos acesso a cópias, ao xerox, como nós temos aqui, eu comecei a passar na lousa. Eu passo na lousa assim um rumo. Olha, essa semana, nós vamos ver isso, isso, isso, eu coloco na lousa especificando... de repente eu percebi que o que eu comecei a fazer lá, é justamente o roteiro. Só que eu estou passando na lousa. Essa é a única diferença. E aí eu explico, faço aquela explicação, tento fazer um "antes da leitura" que eu achei fantástico, que eu acho que chamou mais a atenção deles, pra querer fazer o roteiro... (Prof. 2)

Bom, mudou que eu comecei a me questionar, realmente, qual era a forma de aproximar o texto da criança, como é que você faz pra aproximar uma coisa da outra. Porque, você tá trazendo uma coisa aparentemente desconhecida, mas que ao mesmo tempo está no universo deles, somos seres sociais e culturais, a gente não está totalmente alheio. Então, nesse último roteiro, por exemplo, que eu trouxe as palavras relativas ao processo político, o que eu pude enxergar é que eles identificavam várias palavras dali. Eles podem até não identificar o conceito, mas eles conseguem identificar a palavra, então, a partir da palavra,

ir para o conceito fica mais fácil do que trazer o conceito propriamente, e a partir desse conceito pra que eles consigam desenvolver. (Prof. 3)

A etapa "antes da leitura", sem dúvida, influenciou bastante a prática dos professores, que encontraram por meio dela a possibilidade de contribuir para a aprendizagem dos alunos e de alavancar o momento em que os alunos trabalham em grupos no salão de estudo. A etapa “durante a leitura” também recebeu bastante investimento dos professores, porém, seria necessária uma atenção ainda maior no sentido de explorar os textos não apenas em termos de localização de informações, como ainda se observa em alguns roteiros, mas também quanto às habilidades de inferência e de avaliação. De todo modo, essa etapa se faz presente nos roteiros de estudo e tem exigido dos professores um posicionamento frente aos alunos para esclarecer o aumento do número de páginas dos roteiros, por exemplo.

Quando eles receberam as folhas do roteiro foi assustador. Eu disse "Calma, só colem no caderno. Não é o que vocês estão pensando. Não é nada disso. "Aí durante as explicações na sala de orientação, eu fui lendo com eles, passo a passo, aí, no final, aquele (suspiro de alívio)"... Olha, se vocês forem ver a quantidade de páginas, as atividades, está até menor que os roteiros anteriores. Por quê? Porque vocês vão ter que ler mais, participar mais em grupo, pesquisar na Internet, pesquisar na sala de leitura, vocês tem mais subsídios, só que vocês têm que ler passo a passo, só isso... (Prof. 1)

Na percepção dos alunos, a quantidade de papel que recebem é diretamente proporcional à quantidade de tarefas. Do ponto de vista da assessoria, essa relação não se verifica; ao contrário, roteiros maiores estão relacionados com um detalhamento da mesma tarefa que tinham anteriormente, uma 
explicitação dos focos de estudos. Mais que isso, o fato de os roteiros estarem mais extensos relaciona-se prevalentemente com o cuidado dos professores na orientação da leitura dos textos e da aprendizagem. Portanto, é preciso ajudar os estudantes a compreenderem esse ponto de vista, esclarecendo-os com relação a ele. 0 que os professores fizeram foi justamente isso: chamar a atenção dos alunos quanto a essa perspectiva já na sala de orientação. Mas não só nesse momento esse esclarecimento pode ser feito. Também no salão, os professores têm procurado chamar a atenção dos alunos quanto ao fato de que a dimensão da tarefa continua a mesma, procurando, inclusive, enfatizar o que eles têm a ganhar com o aumento da quantidade de papéis.

Talvez seja possível dizer que, de modo geral, a etapa "depois da leitura" seja aquela que até agora recebeu menos atenção dos professores. Não porque eles a recusem, mas porque é uma etapa que requer dos professores mais esforços na busca por outras fontes textuais, no acompanhamento dos grupos quanto à leitura das mesmas e da qualidade das sínteses elaboradas sobre os textos em suas diferentes formas. Os professores, por diversas vezes, comentaram o fato de que não tem sido fácil dar conta das demandas dos alunos, sobretudo daqueles com dificuldades. Os professores durante o trabalho no salão gostariam de dedicar mais tempo àqueles que são reconhecidamente casos problemáticos, porém isso tem sido difícil frente às muitas solicitações que são feitas nesse espaço.

\section{Revendo o percurso}

O Projeto Heliópolis se propôs a apoiar e a acompanhar os professores dos anos finais do ensino fundamental na elaboração dos roteiros de estudos, de forma que esses pudessem articular efetivamente as disciplinas de uma mesma área do conhecimento.

É possível afirmar que as ações desenvolvidas e as escolhas feitas durante o processo de intervenção da assessoria possibilitou considerável avanço, em termos da relação forma-conteúdo nos roteiros de estudos. Apontaram-se também ganhos na prática dos professores na construção e aperfeiçoamento de saberes docentes, sobretudo quanto ao conhecimento didático do conteúdo, o conhecimento do aluno e o conhecimento do próprio conteúdo que ensina.

De modo geral, pode-se considerar que o processo de assessoria teve êxitos, não apenas no que se refere às mudanças nos roteiros de estudo, 
mas também no que se refere ao trabalho coletivo do grupo escola. Deve-se considerar que mudanças nos roteiros, bem como na dinâmica do coletivo da escola já eram demandas que a escola manifestou por ocasião da avaliação realizada pelo CENPEC em 2010. Em 2011, o processo de assessoria investiu justamente no sentido de melhor compreender essas demandas, interpretálas e problematizá-las junto aos profissionais da escola. Esse processo foi constituindo-se ao longo de 2011 de forma participativa, de modo que tanto a equipe do CENPEC como a da escola precisaram compatibilizar entre si suas próprias demandas.

Do lado da equipe do CENPEC, em particular, foi preciso cuidar para que uma visão informada demais, isto é, convicções e “certezas" não atropelassem a implementação de inovações requeridas seja no nível do individual, seja no nível do grupo. Essa forma de conduzir a assessoria foi percebida por vários profissionais da escola, sobretudo, nos depoimentos dos professores.

[...] vocês não vieram com uma coisa pronta. Isso foi legal. Começou por aí. Eu já gostei do CENPEC por conta disso. Não veio. Não foi uma coisa com sempre vem, lá de cima, e nós aqui em baixo temos que dizer amém e engolir. Então foi muito bacana, porque vocês tiveram que aprender o que nós já estávamos fazendo e começar daí. Vocês não vieram desconstruindo, percebe? Vocês vieram nos ajudar a continuar. (Prof. 1)

O conjunto das ações desenvolvidas no âmbito do projeto se pautou, em todo o percurso, pela realização das ações de forma colaborativa. Assim foi o trabalho realizado na reelaboração dos roteiros, na assessoria à coordenação pedagógica, bem como nas tomadas de decisões nas reuniões de gestão compartilhada. Com base nas informações coletadas por meio dos registros de campo, das entrevistas com os professores, dos resultados das avaliações, dos encontros de formação e das conversas informais, pode-se afirmar que a opção por um processo colaborativo de assessoria foi decisivo para alcançar os resultados já apontados, num período relativamente pequeno de tempo.

É possível, ainda, afirmar que os encaminhamentos e as escolhas da assessoria para esses momentos de intervenção favoreceram a explicitação por parte dos professores de um sentimento de pertencimento a um grupo.

Mas o mais interessante que eu acho nesse momento, é a questão da união dos professores, eu sinto isso muito forte... ainda tem aquelas coisas, cada um faz o seu, porém, a gente sente, começa a ter uma ligação. (Prof. 2)

Por outro lado, há que se considerar os avanços no coletivo da escola, tendo em vista o tempo previsto de vigência do projeto que era de um ano. 
Em síntese, cabe reafirmar que, ao conseguir captar, interpretar e agir sobre as demandas e desafios gerados durante o processo de assessoria e se pautar por uma forma coletiva de encaminhar e fazer escolhas, respeitando o processo do grupo, a assessoria se constituiu com legitimidade junto à equipe da escola para uma parceria produtiva por um ensino competente na EMEF Presidente Campos Salles, no bairro de Heliópolis. 


\section{Project Heliópolis: explaining learning expectations and building reading scripts in the context of educational innovation}

Abstract: This text discusses the background and results of an advising project executed by Cenpec at a municipal public school located in the Heliópolis district, in the municipality of São Paulo, whose Educational Policy Project established construction of close community relations, understanding that the school can play a role as an agent of social change. Using this guideline and in an effort to resolve the more immediate consequences of faculty absenteeism - such as the need to send students home - the school underwent a huge overhaul of its internal organization, adopting the Escola da Ponte of Portugal as a model. Students no longer needed to be sent home, but there was a new challenge: professionally train teachers so that they could teach under new conditions. Cenpec was called on to intervene in this context and, after diagnosing possibilities and limitations, it chose a project that would outline expectations for teachers regarding learning and constructionof reading scripts.

Keywords: Escola da Ponte. Learning expectations. Reading scripts. 


\section{REFERÊNCIAS}

CARVALHO, J. S. F. de. A qualidade de ensino vinculada à democratização do acesso à escola. Estudos Avançados. São Paulo, v. 21, n. 60, Ago. 2007.

FRANCO, M. A. S. Pedagogia da Pesquisa-Ação. Educação e Pesquisa. São Paulo, v.31, n.3, p.483-502, set/dez.2005.

NÓVOA, A. Professores: imagens do futuro presente. EDUCA. Instituto de Educação. Lisboa: Universidade de Lisboa. Portugal, 2009.

PACHECO, J. F. Entrevista ao site educacional.com.br. Disponível na internet http://www.educacional.com.br/entrevistas/entrevista0043.asp. Acessado em outubro de 2012.

PONTE, J. P. Da formação ao Desenvolvimento Profissional. Prof Mat 98, Actas. Lisboa: APM Associação de Professores de Matemática, 1998.

SOLÉ, I. Estratégias de Leitura. Porto Alegre: Artmed, 2000.

ZEICHNER, K.M.; DINIZ-PEREIRA, J. E. Pesquisa dos educadores e formação docente voltada para a transformação social. Cadernos de Pesquisa, v. 35, n. 125, maio/ago. 2005.

RECEBIDO: Janeiro de 2013.

APROVADO: Junho de 2013. 